\title{
Kasvien fytoremediaatiopotentiaali CCA:Ila saastuneen maan puhdistuksessa
}

\author{
Petra Manninen-Egilmez ${ }^{1}$, Pirjo Mäkelä ${ }^{1}$, Helinä Hartikainen ${ }^{2}$, Arja Santanen ${ }^{1}$, Mervi Seppänen ${ }^{1}$, \\ Frederick Stoddard ${ }^{1}$, Markku Yli-Halla ${ }^{2}$ \\ ${ }^{1}$ Helsingin Yliopisto, Soveltavan biologian laitos, PL 27, 00014 Helsingin Yliopisto, \\ petra.manninen@helsinki.fi,pirjo.makela@helsinki.fi,arja.santanen@helsinki.fi. \\ mervi.seppanen@helsinki.fi.frederick.stoddard@helsinki.fi \\ ${ }^{2}$ Helsingin Yliopisto, Soveltavan kemian ja mikrobiologian laitos, PL 27, 00014 Helsingin Yliopisto, \\ helina.hartikainen@helsinki.fi,.markku.yli-halla@helsinki.fi
}

\section{Tiivistelmä}

Maaperän saastuminen on maailmanlaajuinen ympäristöongelma. Ihmisen toiminnan tuloksena esimerkiksi raskasmetalleilla pilaantuneita maa-alueita on runsaasti. CCA (chromated copper arsenate) on maailmalla laajasti käytetty puun kyllästysaine, joka on saastuttanut laajoja maa-alueita $\mathrm{mm}$. sahalaitoksilla, tehdasalueilla ja kaatopaikoilla. Kuparin, kromin ja arseenin yhtäaikainen esiintyminen vaikeuttaa maan puhdistamista kemiallisesti. Tästä johtuen fytoremediaatiomenetelmät näyttäisivät olevan paras vaihtoehto CCA:lla saastuneiden maiden puhdistamiseksi.

Fytoremediaatiolla tarkoitetaan maanperän puhdistamista kasvien avulla. Tutkimuksen tarkoituksena oli tutkia kasvien kykyä puhdistaa maaperää haitta-aineista. Kokeessa kasvatettiin eri kasvilajeja sekä selvitettiin niiden kestävyys raskasmetalleja vastaan sekä kyky ottaa raskasmetalleja maasta.

Raskasmetallien kertyminen eri kasvinosiin sekä biomassan muodostus määritettiin. Biomassan muodostumisen sekä kasvien raskasmetallipitoisuuden avulla arvioitiin kasvien fytoremediaatiopotentiaali. Kasveista havainnoitiin lisäksi lehtialan muodostus, itävyys juurinystyröiden muodostus, juurien rakenne ja anatomia, vesisuhteet, yhteyttäminen, ravinnepitoisuus. Lisäksi tutkitaan antioksidanttiaktiivisuutta, raskasmetallien lokalisoitumimista, fytokelatiinien muodostusta sekä määritetään kasvien tuhkapitoisuus ja koostumus.

Astiakokeissa lupiinit tuottivat noin kolme kertaa suuremman biomassan verrattuna hamppukasveihin. Kupari kerääntyi eniten valko- ja sinilupiinin lehtiin, keltalupiinin korsiin sekä hampun lehtiin ja siemeniin. Kromia kerääntyi lehtiin ja korsiin, mutta ei palkoihin ja siemeniin. Arseeni kerääntyi suurimmaksi osaksi lupiinien lehtiin sekä hampun korsiin, mutta sitä löydettiin huomattavasti kohonneina pitoisuuksina jokaisesta kasvinosasta. Raskasmetalleista arseenin konsentraatio lisääntyi selvästi maan arseenipitoisuuden kasvaessa. Kasveilla näyttäisi sen sijaan olevan raja kuinka paljon kasvi kykenee ottamaan kuparia. Raskasmetalleista kromin otto oli rajoitettua ja se näyttäisi haittaavan eniten kasvua.

Hamppu ja lupiini näyttäisivät soveltuvan fytoremediaatioon alueilla, joilla saastuneen maan konsentraatio on alle $200 \mathrm{mg} \mathrm{kg}$ mata. Viljelemällä kasveja CCA-aineilla pilaantuneilla mailla voitaisiin puhdistaa maata sekä käyttää kasvimateriaali bioenergian lähteenä sekä lisäksi vähentää raskasmetallien ja metalloidien huuhtoutumista estämällä eroosion muodostuminen.

Asiasanat: fytoremediaatio, biomassa, lupiini, hamppu, raskasmetallit, bioenergia 


\section{Johdanto}

CCA (Chromated copper arsenate) on maailmalla laajasti käytetty puun kyllästysaine, joka on 1930 luvulta asti saastuttanut maa-alueita kuparilla, kromilla sekä arseenilla (Aceto \& Fedele, 1994). Ongelma CCA:1la saastuneessa maassa on edellä mainittujen aineiden esiintyminen yhtäaikaisesti, joka vaikeuttaa maan fysikaalis- kemiallista puhdistusta (Lombi ym. 2004). Fytoremediaatiomenetelmät näyttäisivätkin olevan paras vaihtoehto CCA:1la saastuneiden maiden puhdistamiseksi. Kuparin, kromin sekä arseenin vaikutuksia kasveissa sekä fytoremediaatiota on tutkittu erikseen, mutta niiden yhtäaikainen vaikutus on edelleen epäselvä.

Fytoremediaatio käsitää useita eri menetelmiä, joissa kasveja käytetään hyödyksi puhdistettaessa saastuneita maa-alueita, vesialueita ja ilmaa (Cunnigham ym. 1995). Kiinnostus fytoremediaatiotekniikoihin on ollut lisääntyvän mielenkiinnon kohteena sillä se sisältää suuria ekonomisia mahdollisuuksia. Menetelmät ovat huomattavasti halvempia verrattuna perinteisiin puhdistusmenetelmiin (Raskin ym. 1997). Yksi fytoremediaatiomenetelmistä on fytoekstraktio. Fytoekstraktiossa kasvit keräävät haitta-aineita korjattavaan kasvustoon. Tästä johtuen käytettävän kasvin tulee ottaa juuriston avulla saasteita maasta sekä siirtää ne versoon (Cunnigham ym. 1995). Ihanteellinen kasvi fytoekstraktioon kasvaa saastuneessa maassa tuottaen suuren biomassan sekä korkean raskasmetallipitoisuuden maanpäällisiin kasvinosiin (Cunnigham et al. 1995). Valitettavasti luonnossa tavattavat hyperakkumulaattorikasvit ovat usein hidaskasvuisia sekä tuottavat alhaisen vuotuisen biomassan (Khan. et al. 2001). Tästä johtuen fytoremediaatiossa voidaan keskittyä kasveihin, jotka tuottavat suuren biomassan, mutta kuuluva keskinkertaisiin saasteiden kerääjiin (Ebbs et al. 1997). Näin kyettäisiin poistamaan korkeampia pitoisuuksia haitta-aineita. Hamppu on nopeakasvuinen tuottaen suuren biomassan. Se sopeutuu helposti erilaisiin ympäristöolosuhteisiin ja omaan syvän juuriston (Small \& Marcus 2002). Hampun on myös todettu keräävän kuparia, kadmiumia, lyijyä ja sinkkiä maasta (Angelova et al. 2004). Valkolupiinit selviytyvät matalassa pH:ssa ja alhaisessa ravinnepitoisuudessa. Niiden on myös todettu keräävän arseenia maasta ((Vazquez et al. 2006).

Tutkimuksessa tutkittiin raskasmetallien kerääntymistä sekä jakautumista versossa. Tutkimuksen tarkoituksena oli selvittää hamppujen ja lupiinien fytoremediaatiopotentiaali sekä soveltuvuus fytoremediaatioon sekä määrittää niiden toleranssi raskasmetalleja (kupari, kromi ja arseeni) vastaan. Lisäksi tutkitaan mahdollisuutta käyttää kasvimateriaali bioenergian raaka-aineeksi. Fytoremediaatiopotentiaali kertoo kasvin kyvystä puhdistaa saastunutta maata. Sitä voidaan arvioida, kun tiedetään eri kasvinosien biomassa sekä kasvinosien raskasmetallipitoisuudet.

\section{Materiaalit ja menetelmät}

Kuusi erillistä astiakoetta järjestettiin Helsingin yliopiston soveltavan biologian laitoksella vuosina 2007-2009. Kokeet järjestettiin täydellisesti satunnaistettuna kasvihuoneessa ja toistojen määrä oli 4-8.

Ensimmäisessä kokeessa käytettiin öljyhamppua (Cannabis sativa L.), valkolupiinia (Lupinus albus L.) ja keltalupiinia (Lupinus luteus L.). Edellisten lisäksi toisessa kokeessa olivat mukana kuituhamppu (Cannabis sativa L.) ja sinilupiini (Lupinus angustifolius). Lopuissa kokeissa käytettiin ainoastaan valkolupiinia ja kuituhamppua. Kasvit kylvettiin hiekkamaahan $7.5 \mathrm{~L}$ astioihin. Peruslannoituksena annettiin typpeä hampuille $150 \mathrm{mg} \mathrm{N} \mathrm{ja} \mathrm{lupiineille} 70 \mathrm{mg} \mathrm{N} \mathrm{kg}^{-1}$ sekä molemmille $40 \mathrm{mg} \mathrm{P} \mathrm{kg}{ }^{-1}$ ja $100 \mathrm{mg} \mathrm{K} \mathrm{kg}^{-1}$ (KS, Puutarhan täyslannos ja MgS, Kemira Grow How). Astioihin lisättiin raskasmetalleja seuraavina pitoisuuksia: Cu:Cr:As 50:50:15, 100:100:5, 300:150:50, 200:300:100 ja 1000:1500:500 mg kg-1. Kahdessa kokeessa kuituhamppua ja valkolupiinia kasvatettiin ainoastaan yhdessä haitta-aineessa 1,0 L astioissa nousevina konsentraatioina $\mathrm{Cu}$ : 50, 100, 200, 300, 400, 600, 800 ja $1000 \mathrm{mg} \mathrm{kg}^{-1}$; Cr: 50, 100, 200, 300, 400, 600, 800,1000 ja $1200 \mathrm{mg} \mathrm{kg}^{-1}$; As: 5, 15, $25,50,75,100,150,200,300$ ja $400 \mathrm{mg} \mathrm{kg}^{-1}$. Vertailun vuoksi myös konsentraatiokokeessa oli mukana myös CCA pitoisuudet Cu:Cr:As 50:50:15 ja 100:100:5 mg/kg. Raskasmetallit lisättiin astioihin seuraavina yhdisteinä: Kupari $\mathrm{CuSO}_{4}$, Kromi $\mathrm{K}_{2} \mathrm{Cr}_{2} \mathrm{O}_{7}$ ja Arseeni $\mathrm{Na}_{2} \mathrm{HAsO}_{4}$.

Siemenet kylvettiin astioihin ja kasvit harvennettiin 4-5 kasvia/astia noin kaksi viikkoa kylvöstä. Konsentraatiokokeessa astioissa kasvoi ainoastaan yksi kasvi. Kasvihuoneolosuhteet vakioitiin 
PRIVA- säätöautomatiikalla. Päivänpituus oli 16 h, PPFD noin $400 \mu \mathrm{mol}$ ja lämpötila säädetty noin $21^{\circ} \mathrm{C}$. Kasveista määritettiin biomassan muodostuminen eri kasvinosista (lehdet, juuret, korret, siemenet ja palot) sekä lehtiala (LI-3000-A Licor Inc. USA) viisi kertaa kasvukauden aikana. Konsentraatiokokeessa biomassa mitattiin ainoastaan kokeen lopussa. Näytteitä kuivattiin uunissa 80 ${ }^{\circ} \mathrm{C}$ :ssa kahden vuorokauden ajan, jonka jälkeen niiden kuivapaino punnittiin. Kuivat näytteet jauhettiin raskasmetallipitoisuuden määrittämistä varten. Raskasmetallit analysoitiin ICP:1la (Thermo Jarrel Ash, IRIS Advantage). Kromin ja Kuparin määritykseen käytettiin laitetta ICP-OES ja Arseenin ICP-MS.

\section{Tulokset ja tulosten tarkastelu}

\section{Biomassa}

Kaksi suurinta CCA- raskasmetallitasoa olivat liian korkeita kasvien kasvulle. Suurimmassa $(\mathrm{Cu}: \mathrm{Cr}: A S$ 1000:1500:500) tasossa siemenet eivät itäneet. Toiseksi korkeimmassa tasossa (Cu:Cr:As) 200:300:100 kasvien kasvu pysähtyi kasvien ollessa noin $30 \mathrm{~cm}: n$ pituisia. Sen sijaan muissa käytetyissä konsentraatiossa kasvit selviytyivät. Raskasmetallitasoissa kasvien kasvu oli tosin epätasaisempaa verrattuna kontrollikasveihin sekä alhaisimpaan CCA-tasoon (Cu:Cr:As 50:50:15), mutta kasvit tuottivat kuitenkin hyvän biomassasadon. Öljyhamppu tuotti jopa suuremman biomassa alhaisimmassa tasossa (50:50:15) verrattuna kontrollikasveihin. Myös konsentraatiokokeessa kasvit tuottivat suuremman biomassan kasvaessaan lievästi saastuneessa maassa. Tämä ilmeni käytettäessä niin arseenia, kuparia kuin kromiakin (Taulukko 2).

Kasvihuoneessa lupiinit tuottivat noin kolme kertaa suuremman kokonaisbiomassan verrattuna hamppukasveihin (Kuva 1). Tämä johtui lähinnä palkojen suuresta painosta, jotka käsittivät noin 60$70 \%$ lupiinikasvien biomassasta. Konsentraatiokokeessa sadonkorjuu suoritettiin viiden viikon kuluttua itämisestä. Tällöin hamppujen biomassa oli vielä suurempi kuin lupiinien. Hamppujen biomassasta suurin osa oli korsissa. Valkolupiinin ja Keltalupiinin kontrollitason biomassoissa ei havaittu eroja, mutta keltalupiinin sato reagoi herkemmin maan raskasmetallipitoisuuteen alentaen satoa. Sinilupiini oli kestävä raskasmetalleja vastaan, mutta tuottivat noin $75 \%$ alhaisemman biomassan verrattuna muihin lupiinilajeihin. Kuituhamppu taas tuotti öljyhamppua suuremman biomassan. 

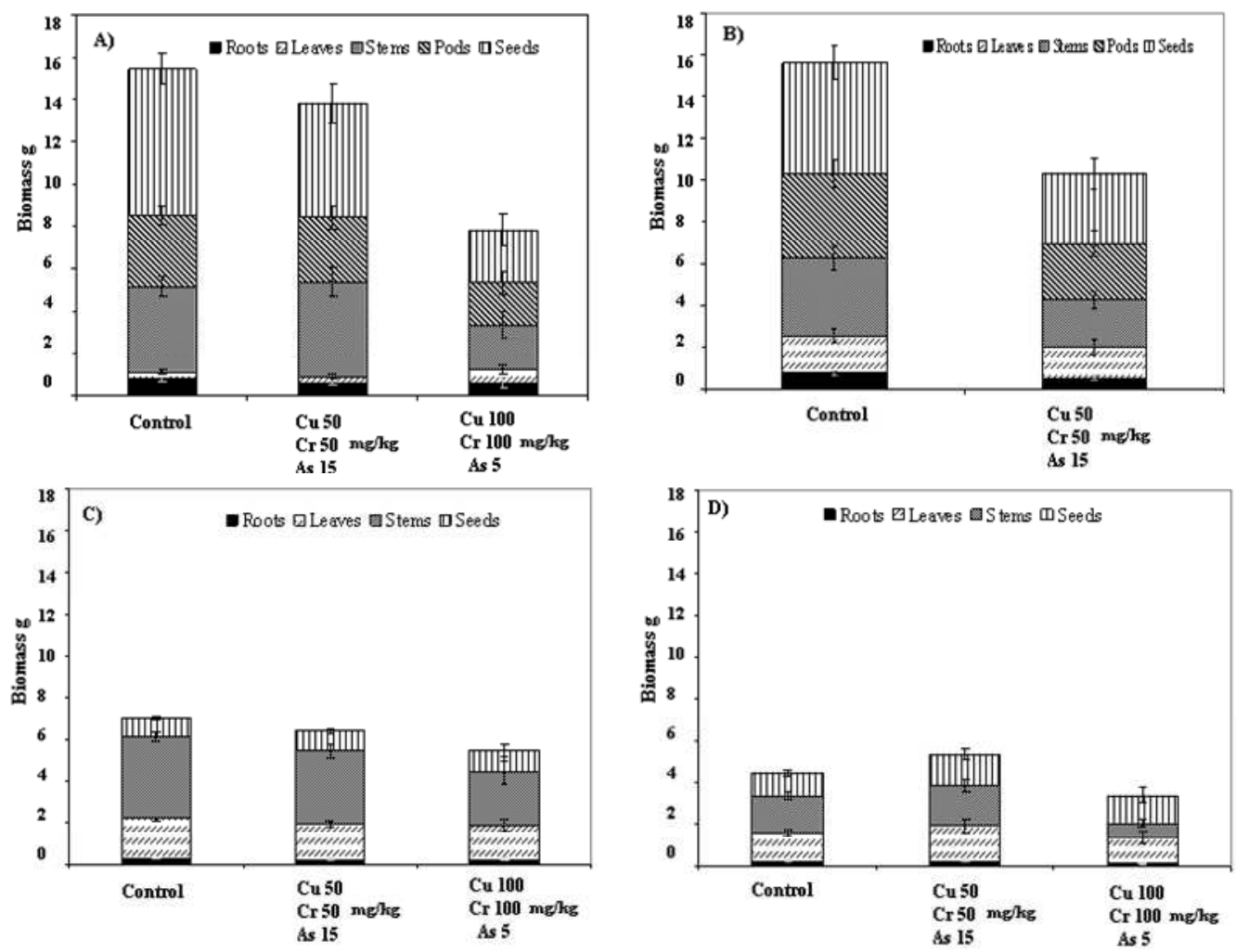

Kuva 1. Kontrollimaassa sekä kuparilla, kromilla ja arseenilla saastuneessa maassa kasvaneiden A) valkolupiinin, B) keltalupiinin, C) kuituhampun ja D) öljyhampun kasvinosien kuivapaino. Tulokset ovat kahdeksan kerranteen keskiarvoja, \pm SE, n=19-40

\section{Raskasmetallipitoisuus}

Sekä kasvilaji että raskasmetalli vaikuttivat mihin kasvinosaan raskasmetallit kerääntyivät (Kuva 2). Kupari kerääntyi eniten valko- ja sinilupiinin lehtiin, keltalupiinin korsiin sekä hampun lehtiin ja siemeniin. Kuituhampun korsien kuparipitoisuus oli korkeampi aikaisemmin kasvukaudella. Myöhemmin kasvukaudella hamput siirsivät kuparin kuitenkin siemeniin. Kasvit myös sietivät hyvin maan kuparipitoisuutta. Kasvu hidastui vasta kun maan pitoisuus oli n. 600-800 mg/kg. Kasveilla näyttäisi olevan raja kuinka paljon kasvi kykenee ottamaan kuparia. Tosin kun maan kuparikonsentraatio oli tarpeeksi korkea $(600-1000 \mathrm{mg} / \mathrm{kg})$ kasvien kuparipitoisuus nousi osalla kasveilla korkeaksi, mutta hajonta oli suurta (Taulukko 2).

Arseeni kerääntyi suurimmaksi osaksi lupiinien lehtiin sekä hampun korsiin, mutta sitä löydettiin huomattavasti kohonneina pitoisuuksina jokaisesta kasvinosasta. Raskasmetalleista arseenin konsentraatio lisääntyi selvästi maan arseenipitoisuuden kasvaessa. Tämä huomattiin myös konsentraatiokokeessa, jossa kasvit sietivät hyvin maan arseenipitoisuutta $100-300 \mathrm{mg} / \mathrm{kg}$ asti (Taulukko 2). Arseenin pitoisuus kasvissa lisääntyi kasvukauden edetessä. Suurimmat pitoisuudet löytyivät valkolupiinin lehdistä. Valkolupiinin tulisikin antaa kasvaa mahdollisimman pitkään, mutta kerätä sato ennen kuin lehdet ehtivät putoamaan.

Kromi kerääntyi lehtiin ja korsiin. Korkeimmat pitoisuudet löytyivät kuitenkin valkolupiinin paloista, mutta siemeniin kromi ei kulkeutunut yhtään. Kromin määrä kuituhampulla ja valkolupiinilla lisääntyi kasvukauden edetessä ja kasvit siirsivät kromin tehokkaasti korsista lehtiin. Tosin sadonkorjuussa myös korsien kromipitoisuus lisääntyi, varsinkin kasvatettaessa korkeammissa kromitasoissa. Raskasmetalleista kromin otto oli rajoitettua ja se näyttäisi haittaavan eniten kasvua. Kasvien kasvu häiriintyi jo maan kromitason ollessa 100- $200 \mathrm{mg} / \mathrm{kg}$. Tätä korkeammassa pitoisuudessa kasvaneet kasvit kuolivat muutamassa päivässä. 

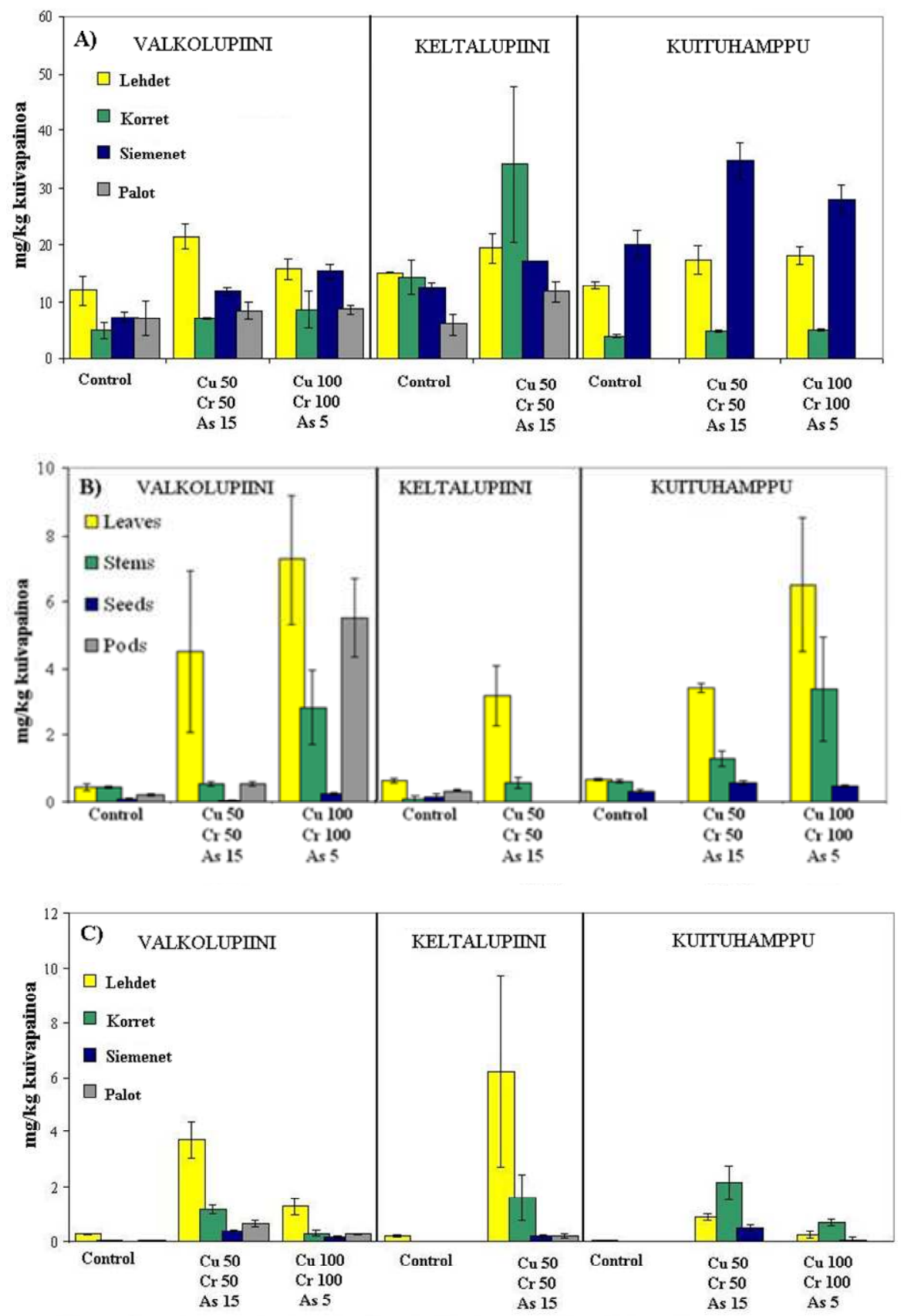

Kuva 2. Valkolupiinin, keltalupiinin sekä kuituhampun A) kuparin, B) kromin sekä C) arseenin maanpäällisten kasvinosien raskasmetallipitoisuudet $(\mathrm{mg} / \mathrm{kg}$ kuivapainosta) eri raskasmetallitasoissa. Tulokset ovat kolmesta kerranteesta \pm SE, $n=4-8$. 


\begin{tabular}{lcc}
\hline $\begin{array}{l}\text { konsentraatio } \\
\text { maassa mg/kg }\end{array}$ & $\begin{array}{c}\text { As } \\
\text { mg/kg/kasvi }\end{array}$ & $\begin{array}{c}\text { Biomassa } \\
\boldsymbol{g}\end{array}$ \\
\hline Valkolupiini & & \\
Control & $0,15 \pm 0,04$ & $3,94 \pm 0,89$ \\
As 5 & $1,13 \pm 0,17$ & $4,30 \pm 0,99$ \\
As 15 & $2,71 \pm 0,08$ & $3,91 \pm 0,42$ \\
As 100 & $14,30 \pm 15,98$ & $2,84 \pm 1,48$ \\
Kuituhamppu & & \\
Control & $0,13 \pm 0,01$ & $6,57 \pm 0,85$ \\
As 5 & $2,90 \pm 0,38$ & $4,13 \pm 0,91$ \\
As 15 & $4,68 \pm 0,89$ & $4,32 \pm 2,03$ \\
As 300 & $\mathbf{2 2 , 8 3} \pm \mathbf{5 , 4 8}$ & $\mathbf{1 , 6 3} \pm \mathbf{0 , 6 2}$ \\
& & \\
\hline konsentraatio & $\boldsymbol{C u}$ & $\mathbf{B i o m a s s a}$ \\
maassa $\mathbf{m g} / \boldsymbol{k g}$ & $\mathbf{m g} / \boldsymbol{k g} / \boldsymbol{k a s v i}$ & $\boldsymbol{g}$ \\
\hline Valkolupiini & & \\
Control & $5,53 \pm 1,74$ & $3,94 \pm 0,89$ \\
Cu 50 & $6,70 \pm 0,70$ & $4,35 \pm 0,29$ \\
Cu 100 & $7,10 \pm 0,82$ & $4,36 \pm 0,26$ \\
Cu 600 & $23,00 \pm 12,00$ & $1,94 \pm 1,75$ \\
Cu 1000 & $206,33 \pm 172,97$ & $0,86 \pm 1,32$ \\
Kuituhamppu & & \\
Control & $6,70 \pm 2,36$ & $6,57 \pm 0,85$ \\
Cu 50 & $7,13 \pm 0,81$ & $7,64 \pm 0,54$ \\
Cu 100 & $7.90 \pm 0,20$ & $8,36 \pm 0,87$ \\
Cu 600 & $62,67 \pm 84,32$ & $3,93 \pm 4,12$ \\
\end{tabular}

\begin{tabular}{lcc}
\hline $\begin{array}{l}\text { konsentraatio } \\
\text { maassa } \mathbf{m g} / \boldsymbol{k g}\end{array}$ & $\begin{array}{c}\boldsymbol{C r} \\
\mathbf{m g} / \mathbf{k g} / \mathbf{k a s v i}\end{array}$ & $\begin{array}{c}\text { Biomassa } \\
\boldsymbol{g}\end{array}$ \\
\hline Valkolupiini & & \\
Control & $0,13 \pm 0,23$ & $3,94 \pm 0,89$ \\
Cr 50 & $1,10 \pm 0,10$ & $4,42 \pm 0,28$ \\
Cr 100 & $3,50 \pm 3,55$ & $1,93 \pm 1,75$
\end{tabular}

\begin{tabular}{lcccc}
\hline $\begin{array}{c}\text { konsentraatio } \\
\text { maassa } \mathbf{m g} / \mathbf{k g}\end{array}$ & $\begin{array}{c}\boldsymbol{A s} \\
\mathbf{m g} / \mathbf{k g} / \mathbf{k a s v i}\end{array}$ & $\begin{array}{c}\boldsymbol{C r} \\
\mathbf{m g} / \mathbf{k g} / \mathbf{k a s v i}\end{array}$ & $\begin{array}{c}\boldsymbol{C u} \\
\boldsymbol{m g} / \boldsymbol{k g} / \mathbf{k a s v i}\end{array}$ & $\begin{array}{c}\text { Biomassa } \\
\boldsymbol{g}\end{array}$ \\
\hline Valkolupiini & & & & \\
Control & $0,15 \pm 0,04$ & $0,13 \pm 0,01$ & $5,53 \pm 1,74$ & $3,94 \pm 0,89$ \\
CCA 50:50:15 & $0,87 \pm 0,21$ & $1,57 \pm 0,90$ & $6,57 \pm 1,03$ & $3,93 \pm 0,29$ \\
CCA 100:100:5 & $0,34 \pm 0,15$ & $3,23 \pm 1,64$ & $6,90 \pm 0,75$ & $3,66 \pm 0,88$ \\
Kuituhamppu & & & & \\
Control & $0,13 \pm 0,01$ & $0,47 \pm 0,15$ & $6,70 \pm 2,36$ & $6,57 \pm 0,85$ \\
CCA 50:50:15 & $1,02 \pm 0,35$ & $0,90 \pm 0,62$ & $12,37 \pm 4,98$ & $5,73 \pm 0,00$ \\
CCA 100:100:5 & $0,51 \pm 0,19$ & $1,07 \pm 0,90$ & $8,10 \pm 1,71$ & $6,12 \pm 2,01$
\end{tabular}

Taulukko 2. Eri arseeni, kupari ja kromi konsentraatioissa sekä niiden yhdistelmissä kasvaneiden valkolupiinin ja kuituhampun arseenipitoisuudet (mg/kg/kasvi) sekä biomassa(g) viiden viikon jälkeen kylvöstä. raskasmetallipitoisuudet: kolme kerrannetta, $\pm \mathrm{STD}, \mathrm{n}=3$. Biomassa: neljä kerrannetta, $\pm \mathrm{STD}, \mathrm{n}=4$. 


\begin{tabular}{lccc}
\hline $\boldsymbol{m g} / \boldsymbol{k g}$ & \multicolumn{1}{c}{ FYTOREMEDIAATIO POTENTIAALI $\boldsymbol{\mu g}$ /kasvi } \\
\hline & Valkolupiini & Keltalupiini & Kuituhamppu \\
KUPARI & & & 57,5 \\
Kontrolli & 98,3 & 122,5 & 79,5 \\
Cu50, Cr5, As 15 & 127,5 & 194,7 & 70,5 \\
Cu100, Cr100, As5 & 82,8 & ei mitattu & 3,9 \\
KROMI & & & 10,9 \\
Kontrolli & 3,3 & 3,6 & 19,5 \\
Cu50, Cr5, As 15 & 5,4 & 6,1 & 0,3 \\
Cu100, Cr100, As5 & 21,7 & ei mitattu \\
ARSEENI & & & 9,5 \\
Kontrolli & 0,7 & 0,6 & 2,3 \\
Cu50, Cr5, As 15 & 10,7 & 14,4 & \\
Cu100, Cr100, As5 & 8,6 & ei mitattu & \\
\hline
\end{tabular}

Taulukko 1. Valkolupiinin, keltalupiinin sekä kuituhampun fytoremediaatiopotentiaali ( $\mu \mathrm{g} / \mathrm{kasvi}$ ) puhdistettaessa kuparilla, kromilla ja arseenilla saastunutta maata. Potentiaali on laskettu kasvinosien kuivapainon sekä niiden raskasmetallipitoisuuksien avulla.

\section{Johtopäätökset}

Hamppu ja lupiini näyttäisivät soveltuvan fytoremediaatioon alueilla, joilla saastuneen maan konsentraatio on alle $200 \mathrm{mg} \mathrm{kg}^{-1}$ maata. Hamput ja lupiini sietävät melko korkeitakin kupari- ja arseenipitoisuuksia, mutta kromi haittaa selvästi kasvien kasvua. Keltalupiinilla oli suurin fytoremediaatiopotentiaali kuparin ja arseenin osalta. Valitettavasti se reagoi muita kasveja herkemmin kromiin. Valkolupiini sekä kuituhamppu osoittivat suurempaa stabiilisuutta kaikkia lisättyjä haitta-aineita vastaan. Viljelemällä kasveja CCA-aineilla pilaantuneilla mailla voitaisiin puhdistaa maata sekä käyttää kasvimateriaali bioenergian lähteenä sekä lisäksi vähentää haittaaineiden huuhtoutumista estämällä eroosion muodostuminen.

Fytoremediaatio vie enemmän aikaa kuin muut puhdistusmenetelmät, sillä käsittelyt on yleensä uusittava useaan kertaan, että saadaan maan haitta-ainepitoisuus toivotulle tasolle. Tästä johtuen fytoekstraktio soveltuukin parhaiten laajoille, mutta ei niin vakavasti saastuneille alueille. Saasteiden poistossa voidaan käyttää hyväkseen eri kasvien erilaista kykyä puhdistaa maata. Tällä on merkitystä puhdistettaessa alueita, jotka ovat saastuneet useammalla kuin yhdellä haitta-aineella.

\section{Kirjallisuus}

Aceto M, Fedele A. (1994). Rain water effect on the release of arsenic chromium and copper from treated wood. Fresenius Environ. Bull. 3:389-394.

Angelova V. (2004). Bio-accumulation and distribution of heavy metals in fibre crops (flax cotton and hemp. Ind. Crops Prod. 19: 197-205.

Cunningham SC, Berti WR, Huang JW. (1995). Phytoremediation of contaminated soils. TIBTECH 13:393397.

Ebbs SD, Lasat MM, Brady DJ, Cornish J, Gordon R \& Kochian LV. 1997. Phytoextraction of Cadmium and Zinc from a Contaminated Soil.” Journal of Environmental Quality 26, 1424-1430.

Khan AG, Kuek C, Chaudry TM, Khoo CS \& Hayes WJ. 2000. The role of plants, mycorrhizoe, and phytochelators in heavy metal contaminated land remediation Chemosphere 41, 197-207.

Li C-X, Feng S-L, Shao Y, Jiang L-N, Lu X-Y, Hou X-L (2007). Effects of arsenic on seed germination and physiological activities of wheat seedlings. J. Environ. Sci. 19:725-732.

Lombi E, Hamon RE, Wieshammer G, McLaughlin MJ \& McGrath SP. 2004. Assessment of the use of industrial by-products to remediate a copper/arsenic contaminated soil.Journal of Environmental Quality 33, 902910.

Raskin, I., Smih, R.RD., Salt, D. 1997. Phyoremediation of metals: using plants to remove pollutants from the environment. Current opinion in Biotechnology 8:221-226.

Small, E., Marcus, D. 2002. Trends in new crops and new uses (Eds. Janick, J., Whipkey, A.) Pp. 284-326.

Vazquez S, Agha R, Granado A, Sarro MJ, Esteban E, Penalosa JM \& Carpena RO. 2006. Use of white lupin plant for pgytostabilization of $\mathrm{Cd}$ and As polluted acid soil. Water, Air, and Soil Pollution 177, 349-365. 